\title{
openheart Delivery preferences for psychological intervention in cardiac rehabilitation: a pilot discrete choice experiment
}

\author{
Gemma Elizabeth Shields (D) , ${ }^{1}$ Stuart Wright, ${ }^{1}$ Adrian Wells, ${ }^{2,3}$ Patrick Doherty, \\ Lora Capobianco, ${ }^{3}$ Linda Mary Davies ${ }^{1}$
}

\begin{abstract}
- Additional supplemental material is published online only. To view, please visit the journal online (http://dx.doi.org/10. 1136/openhrt-2021-001747).

To cite: Shields GE, Wright S, Wells A, et al. Delivery preferences for psychological intervention in cardiac rehabilitation: a pilot discrete choice experiment. Open Heart 2021;8:e001747. doi:10.1136/ openhrt-2021-001747
\end{abstract}

Received 4 June 2021 Accepted 2 August 2021

Check for updates

(C) Author(s) (or their employer(s)) 2021. Re-use permitted under CC BY. Published by BMJ.

${ }^{1}$ Manchester Centre for Health Economics, The University of Manchester, Manchester, UK ${ }^{2}$ School of Psychological Sciences, The University of Manchester, Manchester, UK ${ }^{3}$ Research and Innovation, Greater Manchester Mental Health NHS Foundation Trust, Manchester, UK

${ }^{4}$ Department of Health Sciences University of York, York, UK

Correspondence to Dr Gemma Elizabeth Shields; gemma.shields@manchester. ac.uk

\section{ABSTRACT}

Background Cardiac rehabilitation (CR) is a programme of care offered to people who recently experienced a cardiac event. There is a growing focus on home-based formats of $\mathrm{CR}$ and a lack of evidence on preferences for psychological care in CR. This pilot study aimed to investigate preferences for delivery attributes of a psychological therapy intervention in CR patients with symptoms of anxiety and/or depression.

Methods A discrete choice experiment (DCE) was conducted and recruited participants from a feasibility trial. Participants were asked to choose between two hypothetical interventions, described using five attributes; intervention type (home or centre-based), information provided, therapy manual format, cost to the National Health Service (NHS) and waiting time. A separate opt-out was included. A conditional logit using maximum likelihood estimation was used to analyse preferences. The NHS cost was used to estimate willingness to pay for aspects of the intervention delivery.

Results 35 responses were received (39\% response rate) Results indicated that participants would prefer to receive any form of therapy compared with no therapy. Statistically significant results were limited, but included participants being keen to avoid not receiving information prior to therapy $(\beta=-0.270 ; p=0.03)$ and preferring a lower cost to the NHS $(\beta=-0.001 ; p=0.00)$. No significant results were identified for the type of psychological intervention, format of therapy/exercises and programme start time. Coefficients indicated preferences were stronger for home-based therapy compared with centre-based, but this was not significant.

Conclusions The pilot study demonstrates the feasibility of a DCE in this group, it identifies potential attributes and levels, and estimates the sample sizes needed for a full study. Preliminary evidence indicated that sampled participants tended to prefer home-based psychological therapy in CR and wanted to receive information before initiating therapy. Results are limited due to the pilot design and further research is needed.

\section{INTRODUCTION}

The burden associated with cardiovascular diseases globally is considerable; it is the leading cause of mortality and a key cause of disability. ${ }^{1}$ The burden is increasing, with

\section{Key questions}

What is already known about this subject?

- The current evidence base of preference research in cardiac rehabilitation (CR) is heterogeneous in design and study sample and focuses on educational and exercise sessions. It indicates that preferences for home-based CR differ across participant groups.

What does this study add?

- In a sample of people who had symptoms of anxiety and depression following a cardiac event, the study adds evidence on preferences for the delivery of psychological therapy as part of CR and demonstrates that research of this type is feasible. Findings suggest that participants may prefer home-based options, and would like information given prior to starting therapy, but further research is needed.

How might this impact on clinical practice?

- The research indicated that participants were keen to receive psychological therapy as part of $\mathrm{CR}$ (based on response to opt-out). We recommend that practitioners are mindful of patient preferences when offering psychological therapy to CR patients.

prevalent cases of cardiovascular disease doubling between 1990 (271 million cases) and 2019 (523 million). ${ }^{1}$ Subsequently, there is a need for effective and cost-effectiveness healthcare interventions for affected populations. Cardiac rehabilitation $(\mathrm{CR})$ is a supervised programme offered to people following a cardiac event and comprising of exercises, education and psychological care. ${ }^{2}$ Evidence suggests that CR reduces morbidity and improves quality of life, and is often costeffective. $^{23}$

In the UK, around 90000 people start CR annually (2019 figures). ${ }^{4}$ Three-quarters of CR participants in the UK access group-based supervised CR at a healthcare centre. ${ }^{4}$ Though there is evidence to suggest centre-based and home-based delivery modes have equivalent outcomes, a minority of participants have home-based CR $(8.8 \%) .{ }^{45}$ On entry to CR 
around $30 \%$ of people have symptoms of anxiety and around $20 \%$ have symptoms of depression. ${ }^{4}$ Therefore, CR programmes are uniquely placed to provide vital psychological interventions. A meta-analysis identified that psychological interventions added to exercise-based CR were associated with a reduction in symptoms of depressions and cardiac morbidity. ${ }^{6}$ As centre-based and home-based CR are available, psychological intervention is needed across delivery modes.

Discrete choice experiments (DCE) are increasingly used to elicit preferences for healthcare interventions and services. ${ }^{78}$ Within a DCE, participants make choices between hypothetical scenarios that are summarised using key attributes. Each attribute has several levels that account for how the attribute can vary. Stated preference methods are based on the assumption that healthcare interventions and services can be described by a number of attributes and that an individual's valuation of that intervention/service will vary according to their preferences for levels of those attributes. ${ }^{9}$ Responses allow researchers to quantifiably elicit stated preferences.

The current evidence base for preferences in CR is methodologically heterogeneous and focuses on exercise and education activities. Boyde $e t a l$, found preferences were strongest for centre-based programmes providing timely group exercise sessions and one-to-one educational sessions. ${ }^{10}$ While the results indicated that technology delivered exercise and educational sessions would be less popular, preference heterogeneity was noted, and authors discussed that a one-size-fits-all approach may be unsuitable. Kjaer and Gyrd-Hansen reported preference heterogeneity when they focused on preferences for CR activities. ${ }^{11}{ }^{12}$ Activities included physical exercises, personal meetings with a nurse, group counselling, diet guidance and smoking cessation. The authors found that personal meetings were preferred, followed by physical exercise, and nutritional counselling. Preferences differed by gender, and older people (especially men) did not value the offer of CR highly. Whitty et al, found home-based chronic heart failure management plans were preferred by older people, those with a lower income and people living alone. ${ }^{13}$ Tang et al, found people who preferred a home-based setting for CR reported better physical health and exercise capacity. ${ }^{14}$ Overall, the existing evidence suggests preferences for home-based CR is heterogeneous.

There has been a significant increase in home-based CR mode of delivery (23\%-59\%) due to COVID-19 service adaptation. ${ }^{15}$ Given the growing focus on homebased CR formats and the lack of evidence on preferences for psychological care in CR, there is a clear need to investigate patients' preferences for the design of home-based CR to inform future research and intervention design. The present study is part of an National Institute for Health Research-funded programme called PATHWAY aimed at improving psychological outcomes in CR patients using group-based or home-based metacognitive therapy. ${ }^{16-18}$
The PATHWAY Home-MCT feasibility single-blind randomised controlled trial (RCT) investigated the acceptability of delivering metacognitive therapy (MCT) in a home-based format for CR participants with symptoms of anxiety and depression. ${ }^{16}$ The trial recruited people referred to UK National Health Service (NHS) CR programmes with a score of $\geq 8$ in the anxiety and/or depression subscales of the Hospital Anxiety and Depression Scale. Further details on the design and delivery of Home-MCT are available in the trial protocol. ${ }^{16}$ Results of the trial, which will be published separately, will provide evidence on the acceptability and feasibility of delivering the home-based format for metacognitive therapy for a sample of CR participants. The current study is an extension of the feasibility study; a pilot discrete choice experiment recruited from trial participants to investigate preferences for the delivery of psychological therapy in CR.

\section{Aims and objectives}

The primary aim of this study was to explore the preferences of participants in the Home-MCT feasibility study, who have experienced a cardiac event and have symptoms of anxiety and/or depression, for attributes of a psychological therapy intervention in patients. Specific objectives were to:

- Identify which attributes were most important to patients.

- Evaluate the feasibility of recruiting from a trial sample.

- Estimate the sample size needed for a full study.

The results of this pilot DCE will help to inform the design of future studies to explore the preferences of patients for psychological interventions.

\section{METHODS}

The study used a DCE to examine preferences for psychological therapy in CR.

\section{Attributes and levels}

The DCE design (attributes and levels) was constructed following a review of qualitative feedback from the wider programme of work, discussion with the Patient and Public Involvement (PPI) group and through iterative discussions with the trial research team (including clinical experts). ${ }^{19-21}$ Each hypothetical scenario included five attributes: (1) psychological intervention type (focusing on home-based or centre-based), (2) information provided prior to treatment, (3) therapy manual format, (4) cost to the NHS and (5) waiting time. The full characteristics and levels included in the discrete choice experiment design are included in table 1.

The first qualitative attribute was chosen to investigate preferences around whether participants would like to receive home-based or centre-based therapy. The second and third attributes were included as it was judged to be important by the PPI group and because this is something that could easily be addressed in practice if 


\begin{tabular}{|c|c|}
\hline Attribute & Levels \\
\hline $\begin{array}{l}\text { 1. Psychological intervention to be received } \\
\text { alongside your standard cardiac rehabilitation } \\
\text { programme. }\end{array}$ & $\begin{array}{l}\text { 1. Home-based psychological therapy using a manual with occasional telephone support from a healthcare professional. } \\
\text { 2. Home-based psychological therapy using a manual with occasional face-to-face support from a healthcare professional. } \\
\text { 3. Group psychological therapy based in primary or community care (eg, a local general practitioner or NHS clinic) delivered by } \\
\text { a healthcare professional. } \\
\text { 4. Group psychological therapy based in secondary care (eg, at a hospital) delivered by a healthcare professional. }\end{array}$ \\
\hline $\begin{array}{l}\text { 2. The information given to you prior to accepting } \\
\text { and starting treatment that gives you an idea of } \\
\text { what to expect from the therapy. }\end{array}$ & $\begin{array}{l}\text { 1. No information provided. } \\
\text { 2. A printed leaflet of information. } \\
\text { 3. An overview of the therapy from a healthcare provider with a chance to ask questions. } \\
\text { 4. An overview of the therapy from a healthcare provider with a chance to ask questions and a printed leaflet. }\end{array}$ \\
\hline 3. Format of the therapy manual and exercises. & $\begin{array}{l}\text { 1. Printed (paper copy) of the therapy manual and an accompanying audio CD of exercises. } \\
\text { 2. Printed (paper copy) of the therapy manual and an accompanying DVD (video) of exercises. } \\
\text { 3. Printed (paper copy) plus a website based manual and exercises. } \\
\text { 4. Printed (paper copy) plus a smartphone application-based manual and exercises. }\end{array}$ \\
\hline 4. Additional cost to the NHS. & $\begin{array}{l}\text { 1. } £ 0 . \\
\text { 2. } £ 500 . \\
\text { 3. } £ 1000 . \\
\text { 4. } £ 2000 .\end{array}$ \\
\hline 5. Programme start. & $\begin{array}{l}\text { 1. Within } 2 \text { weeks of hospital discharge. } \\
\text { 2. Within } 4 \text { weeks of hospital discharge. } \\
\text { 3. Within } 6 \text { weeks of hospital discharge. } \\
\text { 4. Within } 8 \text { weeks of hospital discharge. }\end{array}$ \\
\hline
\end{tabular}

NHS, National Health Service.

participants did prefer a certain level. Two quantitative attributes were included. Additional cost to the NHS was used to estimate willingness to pay for aspects of design/ delivery of psychological therapy in CR, recognising that costs can be a key driver in healthcare decision-making. Programme start captured waiting times, which has been noted to be important in the literature in relation to enrolment/attendance and health outcomes. ${ }^{22-24}$

\section{Experimental design}

The number of attributes (five), combined with the number of levels (four), gives a large number of scenarios to describe all the possible different combinations of the features of the therapy (estimated as the number of levels to the power of the number of characteristics). For example, a stated preference survey that uses five characteristics with four levels per attribute gives a total of 1024 possible profiles and over 500000 potential DCE questions. It is not feasible to design a survey to assess preferences for all of these scenarios.

To address this, a fractional factorial design was used, to reduce the number of scenarios by selecting a sample of possible combinations that covers the combinations and effects of interest. ${ }^{25}$ A published design catalogue (http://neilsloane.com/oadir/oa.16.5.4.2.txt) and modulo arithmetic were used to generate an efficient, orthogonal fractional factorial design. ${ }^{26}$

A further question asked participants to choose between their preferred scenario and no psychological therapy (opt-out). Opt-out options are helpful in discrete choice experiments because they are more reflective of real life and can help with the interpretation of results. ${ }^{25}$ An example question is provided in figure 1.

Each survey consisted of four sections; basic sociodemographic details (age, gender, ethnicity, employment status and education level), the EQ-5D-5L, the DCE questions (known as choice sets) and a final section for the participants to provide additional information on how long the survey took and to collect any feedback. Participants were not obligated to answer all questions and could choose to skip questions, or in the case of demographics select 'prefer not to answer'. A copy of the survey is included in the online supplemental material 1. EQ-5D values (utility values) were estimated using the crosswalk

\begin{tabular}{|c|c|c|}
\hline Delivery & Therapy $\mathrm{A}$ & Therapy B \\
\hline $\begin{array}{l}\text { Psychological intervention } \\
\text { to be received alongside } \\
\text { your standard cardiac } \\
\text { rehabilitation programme }\end{array}$ & $\begin{array}{c}\text { Home-based } \\
\text { psychological therapy } \\
\text { using a manual with } \\
\text { occasional telephone } \\
\text { support from a healthcare } \\
\text { professional }\end{array}$ & $\begin{array}{c}\text { Home-based } \\
\text { psychological therapy } \\
\text { using a manual with } \\
\text { occasional face to face } \\
\text { support from a healthcare } \\
\text { professional }\end{array}$ \\
\hline $\begin{array}{l}\text { The information given to } \\
\text { you prior to accepting and } \\
\text { starting treatment that } \\
\text { gives you an idea of what } \\
\text { to expect from the } \\
\text { therapy }\end{array}$ & No information provided & $\begin{array}{l}\text { A printed leaflet of } \\
\text { information }\end{array}$ \\
\hline $\begin{array}{l}\text { Format of the therapy } \\
\text { manual and exercises }\end{array}$ & $\begin{array}{c}\text { Printed (paper copy) of } \\
\text { the therapy manual and } \\
\text { an accompanying audio } \\
\text { CD of exercises }\end{array}$ & $\begin{array}{l}\text { Printed (paper copy) of } \\
\text { the therapy manual and } \\
\text { an accompanying DVD } \\
\text { (video) of exercises }\end{array}$ \\
\hline $\begin{array}{l}\text { Additional cost to the } \\
\text { NHS }\end{array}$ & $£ 0$ & $£ 500$ \\
\hline Programme start & $\begin{array}{c}\text { Within } 2 \text { weeks of hospital } \\
\text { discharge }\end{array}$ & $\begin{array}{c}\text { Within } 4 \text { weeks of hospital } \\
\text { discharge }\end{array}$ \\
\hline $\begin{array}{l}\text { C1.1. Of the options } \\
\text { presented above which } \\
\text { do you like most (Tick } \\
\text { one) }\end{array}$ & & \\
\hline
\end{tabular}

C1.2. If you had to choose from the option that you like the most, or no psychological therapy included in your cardiac rehabilitation pathway, which would you choose? (Tick one)

The option I chose above

No psychological therapy

Figure 1 Example question. NHS, National Health Service. 
mapping algorithm, in line with current guidance from the National Institute for Health and Care Excellence. ${ }^{27} 28$

\section{Recruitment}

All participants in the Home-MCT feasibility trial, who had provided informed consent to take part in the trial, and consented to be invited to further research opportunities, were invited. Full trial inclusion and exclusion criteria are reported in the trial protocol. ${ }^{16}$ In brief, participants had to be adults eligible for CR and have clinically significant symptoms of anxiety and/or depression, with a competent level of English language skills. ${ }^{16}$ Participants were sent a paper copy of the survey materials (invitation letter, participant information sheet, instructions, consent to further contact form and questionnaire) by post (with a prepaid return envelope). The invitation letter also contained an online link (set-up using Select Survey) and participants could choose to complete a paper version or an online version. The stated preference survey was sent to participants after their final trial follow-up had been completed. Each participant was offered a $£ 5$ high street gift voucher to acknowledge participation in the DCE study.

\section{Sample size}

Calculating a sample size for a DCE is challenging and researchers need to be confident that the sample size is large enough to detect differences in preferences. ${ }^{29}$ A range of factors need to be considered, including the DCE design (eg, number of attributes and choice sets), as well as preference heterogeneity. ${ }^{29}$ The sample in this pilot survey was restricted to participants in the Home-MCT trial. The results from this pilot study were used to estimate the sample size that would be required to calculate significant preference coefficients in a full DCE study. The estimated minimum sample size required was generated for D-efficient and Bayesian designs in the experimental design software NGene. ${ }^{30}$

\section{Statistical analysis}

The data was analysed using individual choice responses as the dependent variable in the model..$^{31}$ A conditional logit using maximum likelihood estimation was used in the first instance. The coefficients for each attribute indicate the direction of preference for that attribute. Qualitative attributes were effects coded. ${ }^{32}$ The continuous variables were included as linear in the baseline analysis. Tests for non-linearity of these variables were conducted by effects coding the variables and conducting Bayesian Information Criterion (BIC) tests on the non-linear and linear models. ${ }^{33} \mathrm{~A}$ BIC test was also conducted to test whether one constant could be used to represent preferences for therapy compared with opting out or whether separate constants for Therapy A or B were more appropriate.

The marginal rates of substitution (MRS) for each characteristic were calculated to estimate the relative utility of the characteristics. The MRS for each characteristic was estimated by dividing the coefficient for that characteristic by the inverse of the coefficient for the NHS cost characteristic. This allowed the estimation of the relative cost participants were willing to accept for the different features and assess how important they are (ie, Willingness to Pay). The results for each characteristic of the delivery of psychological therapy indicate how important users felt it was in CR. These data will be used to help inform future policy and commissioning decisions. Due to the small sample size in this pilot study, heterogeneity in preferences for the therapy design was not explored in this analysis.

\section{RESULTS \\ Response rate}

Eighty-nine participants from the Home-MCT trial were invited to participate. The first invitation was sent on 5 March 2020, and 20 responses were received. Given the the COVID-19 pandemic at this time, a reminder was sent to participants who had not completed the survey on 30 June 2020 and subsequently a further 15 responses were received. In total, of the 89 participants invited, 35 responses were received ( $39 \%$ response rate). The online survey submission option was unpopular, with only one response received via this means.

In total $80 \%$ of participants $(28 / 35)$ responded to all choice sets and $82.9 \%(29 / 35)$ responded to all opt-out questions. In total, over three-quarters $(27 / 35,77.1 \%)$ of participants had complete data.

\section{Participant demographics}

An overview of DCE participant characteristics is reported in table 2. Note that for the pilot trial the mean age of participants was 59 (SD 7; range 40-84) and 36\% were women.

Participants had been experiencing cardiac problems for a mean of 5.2 years when they completed the questionnaire, and the most reported cardiac problem was a myocardial infarction (heart attack) which was reported by 22 participants $(62.9 \%)$. The number of participants who reported having family affected by cardiac problems $(15,42.9 \%)$ was equal to the number reporting the opposite.

The mean EQ-5D value, which represents health status, was 0.64 (SD 0.27). This is lower than the population norms for people of a similar age; which are 0.804 for the group aged 55-64 and 0.785 for the group aged $65-74 .^{34}$ A breakdown is reported in the online supplemental material 1.

\section{Participant preferences for a psychological intervention}

Table 3 reports the results of the conditional logistic regression analysis. The BIC tests suggested that nonlinear coding of the continuous variables did not add sufficient explanatory power and so linear terms were used. The test also suggested that a model with a constant term for each therapy rather than a single opt in constant was superior. As the constant for Therapy A is larger than that of Therapy B, there is potentially some evidence (ie, 


\begin{tabular}{|c|c|c|}
\hline & $\mathrm{n}$ & $\%$ \\
\hline \multicolumn{3}{|l|}{ Gender } \\
\hline Female & 13 & 37.1 \\
\hline Male & 22 & 62.9 \\
\hline \multicolumn{3}{|l|}{ Age, years } \\
\hline $45-54$ & 4 & 11.4 \\
\hline $55-64$ & 14 & 40.0 \\
\hline $65-74$ & 16 & 45.7 \\
\hline $75-84$ & 1 & 2.9 \\
\hline \multicolumn{3}{|l|}{ Ethnicity } \\
\hline White & 34 & 97.1 \\
\hline Asian/Asian British & 1 & 2.9 \\
\hline \multicolumn{3}{|l|}{ Education } \\
\hline GCSE (or equivalent) or above & 26 & 74.3 \\
\hline No GCSE (or equivalent) & 7 & 20.0 \\
\hline Missing & 2 & 5.7 \\
\hline \multicolumn{3}{|l|}{ Employment status } \\
\hline $\begin{array}{l}\text { Paid employment (including part-time } \\
\text { or full-time) }\end{array}$ & 11 & 31.4 \\
\hline $\begin{array}{l}\text { Unpaid employment/activities } \\
\text { (including voluntary employment, study, } \\
\text { housewife/husband, retired) }\end{array}$ & 22 & 62.9 \\
\hline Unemployed & 2 & 5.7 \\
\hline \multicolumn{3}{|l|}{ Prior experience of psychological therapy } \\
\hline $\begin{array}{l}\text { Previously received psychological } \\
\text { therapy (group or one-to-one) }\end{array}$ & 6 & 17.1 \\
\hline
\end{tabular}

GCSE, General Certificate of Secondary Education.

a larger constant) that participants were disproportionately likely to select the left-hand option, although this was not statistically significant.

The significant positive constants for Therapy A and Therapy B estimated in the conditional logistic regression suggest that participants highly valued receiving therapy (compared with no therapy). Significant results were indicated for two factors; participants disliked having no information about the therapy before it started and disliked therapy options which had a higher cost impact for the NHS. While results indicate preferences are stronger for home-based therapy options, few of the other coefficients in the model were statistically significant, indicating that there were not strong preferences within the pilot sample for therapy design elements. This was to be expected given the pilot design and sample size. A larger sample size is required to better estimate preferences for therapy design to ensure it is designed to best meet patients' needs.

\section{Sample size estimation for a full study}

To estimate the required sample size for a full study of patients' preferences for a home-based psychological therapy, the coefficients estimated in the model in this pilot study were used as prior values to design optimal D-efficient and Bayesian experimental designs. Table 4 outlines the estimated minimum sample sizes to estimate each coefficient.

It is unlikely that the coefficients for printed leaflet or information in a paper copy with a CD could be estimated with a feasible sample size, suggesting it may be worth excluding or redesigning this in future research. However, most coefficients could be estimated with a sample size of 370 or 362 depending on the whether a D-efficient design or Bayesian design was used.

\section{Participant comments}

The mean time to complete the survey reported by participants was $23.87 \mathrm{~min}$ (SD 14.20; range 5-80).

Fifteen participants left comments on the questionnaire, these were often just general thoughts around CR. The most common comment specific to the DCE was around the cost attribute, and how participants considered cost to be very important, for example,

The treatments are far too costly!

In each answer I've taken into account the cost to the NHS. Any form of affordable help by the NHS is preferable to no help at all.

One participant commented that they volunteer at a CR centre and related it to how much people value talking to people with lived experience (peer support). While not captured in this questionnaire (peer group support), it is an option within a separate DCE being undertaken by our research team related to the clinicbased group-MCT trial. ${ }^{1718}$ This information could also prompt ideas for future research, for example, how could peer support be effectively included in home-based CR interventions.

One comment highlighted that in the chosen sample we might have an issue of adaptation.

As I now feel well. I walk every day even in lock down. I don't feel I need any psycholical(sic) help. It was 3 years ago when I had the heart attack. At the time I felt anxious and I could have benefited from help at the time.

People adapt to their illnesses, especially chronic conditions, and this adaptation may affect how they value their health and choices they make about healthcare..$^{35} 36$ This participant describes how they feel psychological support is no longer relevant to them (and subsequently they used the opt-out), but that when the problem first occurred, they would have felt differently; this is likely to mean that their preferences have changed.

Three participants commented on the repetitiveness of the choice sets. An alternative to consider and assess in future research is a blocked design with fewer questions per participant. A single participant noted that there was a lot of information to read up front and that reducing this would be useful, however, this is partly dictated by ethics requirements. 


\section{Table 3 Conditional logistic regression results}

\begin{tabular}{|c|c|c|c|}
\hline Attribute/level & Coefficient & $P$ value & $\begin{array}{l}\text { Willingness To Pay } £ \\
\text { (95\% Cls) }\end{array}$ \\
\hline \multicolumn{4}{|l|}{ Psychological intervention to be received } \\
\hline Home-based with telephone support & 0.076 & 0.528 & $98(-208$ to 404$)$ \\
\hline Home-based with face-to-face support & 0.102 & 0.405 & $131(-179$ to 441$)$ \\
\hline Group face-to-face in primary or community care & -0.085 & 0.493 & $-109(-422$ to 204$)$ \\
\hline Group face-to-face in secondary care & -0.093 & 0.444 & $-120(-428$ to 189$)$ \\
\hline \multicolumn{4}{|l|}{ Information given prior to starting treatment } \\
\hline No information & $-0.270^{*}$ & 0.033 & $-348(-674$ to -21$)$ \\
\hline Printed leaflet & -0.001 & 0.992 & $-2(-299$ to 296$)$ \\
\hline Overview from a healthcare professional & 0.103 & 0.394 & $133(-174$ to 440$)$ \\
\hline Overview from a healthcare professional plus printed leaflet & -0.165 & 0.184 & $-213(-530$ to 104$)$ \\
\hline \multicolumn{4}{|l|}{ Format of therapy and exercises } \\
\hline Paper copy plus CD & -0.005 & 0.965 & $-7(-308$ to 295$)$ \\
\hline Paper copy plus DVD & 0.061 & 0.616 & $78(-227$ to 384$)$ \\
\hline Paper copy plus website & 0.110 & 0.375 & 141 (-172 to 455$)$ \\
\hline Paper copy plus smartphone application & 0.168 & 0.182 & $216(-105$ to 537$)$ \\
\hline \multicolumn{4}{|l|}{ Cost and programme start } \\
\hline National Health Service cost & $-0.001^{*}$ & 0.000 & - \\
\hline Time to start of therapy & -0.043 & 0.166 & $-56(-135$ to 24$)$ \\
\hline \multicolumn{4}{|l|}{ Therapy provision } \\
\hline Constant for Therapy A & $1.950^{\star}$ & 0.000 & 2515 (1843 to 3188$)$ \\
\hline Constant for Therapy B & $1.350^{*}$ & 0.000 & 1741 (1153 to 2328) \\
\hline
\end{tabular}

*Statistical significance $(p<0.05)$

\section{Table 4 Sample size requirements}

\begin{tabular}{|lll}
\hline Attribute/level & Efficient & Bayesian \\
\hline Psychological intervention & & \\
\hline Home-based with telephone support & 290 & 308 \\
\hline Home-based with face-to-face support & 245 & 251 \\
\hline $\begin{array}{l}\text { Group face-to-face in primary or community care } \\
\text { Group face-to-face in secondary care }\end{array}$ & 370 & 362 \\
\hline Information provided & 227 & 228 \\
\hline No information & & \\
\hline Printed leaflet & 41 & 41 \\
\hline Overview from a healthcare professional & 126596 & 120853 \\
\hline $\begin{array}{l}\text { Overview from a healthcare professional plus printed } \\
\text { leaflet }\end{array}$ & 304 & 321 \\
\hline Format of the therapy manual and exercises & 89 & 87 \\
\hline Paper copy plus CD & & \\
\hline Paper copy plus DVD & 39768 & 39841 \\
\hline Paper copy plus website & 960 & 924 \\
\hline Paper copy plus smartphone application & 179 & 190 \\
\hline Additional cost to the National Health Service & 104 & 100 \\
\hline Programme start & 2 & 2 \\
\hline
\end{tabular}

\section{DISCUSSION}

The study aimed to evaluate the feasibility of conducting a DCE to identify preferences for psychological therapy delivery for people who were eligible to attend CR with symptoms of depression and/or anxiety, and to provide an initial indication of preferences. It demonstrated that conducting a survey of this type is feasible, and the study provides an estimate of the sample size needed for a full (larger) study. The initial findings, limited by sample size, indicate that participants tend to prefer home-based therapy, however this was not statistically significant. Two statistically significant findings were identified; participants were keen to receive some information about psychological treatment prior to therapy and preferred lower costs. An opt-out was included but the coefficients indicated that participants would prefer to partake in a therapy versus no therapy.

The participants did not want to receive no information about psychological therapy prior to starting therapy (statistically significant), which highlights a need to provide people with enough information to allow them to make informed choices. The strongest, but not statistically significant, preferences were for receiving an overview of therapy from a healthcare professional. There was some evidence to suggest preferences were stronger for having a paper copy of the manual plus a smartphone application. A published study found technology delivered intervention would be less popular, however, this 
focused on exercise and educational sessions. ${ }^{10} \mathrm{~A}$ questionnaire conducted in people attending CR found respondents were interested in CR delivered via the internet or mobile phones, although interest decreased with age. ${ }^{37}$ Preferences indicted people would prefer therapy to start sooner after hospital discharge, which aligns with a previous study (not specific to psychological therapy) which found stronger preferences for CR starting within 2 weeks. ${ }^{10}$ Participants disliked options with a higher cost to the NHS (statistically significant) which was also reflected in their comments. This aligns with the wider literature, as cost attributes were noted to be important in a systematic review of preference research in anxiety and depression. ${ }^{38}$

There was a reasonable response rate to the survey $(39 \%)$ given that the first invitation was sent just before the COVID-19 pandemic resulted in a UK shutdown. The PPI group were consulted about the response rate and suggested that the target population were more likely to be shielding compared with the general population and subsequently would be hesitant to leave their home for non-essentials (eg, posting the survey back). It was suggested (by the PPI group) that the pandemic may have had varied effects on potential participants; for some people it could have made them more apathetic towards research due to the negative mental health effects, but for others it could have increased engagement as they looked for activities to avoid boredom. Participants were recruited from a trial sample for this pilot, and findings confirm a larger study is possible. Future studies do not need to restrict to trial recruitment and could consider other options (eg, online panels) which may make recruiting a larger sample easier.

There are several limitations to this research. Most substantially, it is limited by the sample size and the lack of diversity in the sample. The number and type of participants recruited for this study are likely to have affected the elicited preferences. As it is a pilot, the sample size is small and restricts the results. Moreover, the type of participants recruited, and the timing of recruitment may have affected preferences. It is possible that selection bias affected the results. We recruited from a trial sample of participants who had experienced symptoms of anxiety and/or depression when they attended CR, this sample may be more favourable towards receiving psychological therapy compared with the general CR population. Participants had symptoms of anxiety and/or depression when they were recruited to the trial, though as the DCE took place after the end of trial follow-up participants may have recovered from their symptoms. A minority (39\%) of the pilot trial participants took part and we do not have any information of the remaining trial participants to explain why they did not return surveys. As mentioned, the study recruited during the COVID-19 pandemic which may have influenced the response rate and the responses, limiting generalisability. The PPI group noted that preferences may have been affected by local and national lockdown restrictions, which may strengthen preferences for home-based intervention. However, the PPI group also discussed how challenging it could be to make time and to share spaces with family members during the pandemic, in a way that would allow someone to partake in home-based psychological therapy privately. In relation to preferences for technology, the group had mixed opinions; with some members commenting on becoming more confident with technology and others experiencing technology fatigue during lockdown.

Many of the previous studies noted that preference heterogeneity affected their results, including whether participants preferred home-based interventions and preferences for technology. ${ }^{10-14}$ Unfortunately, this could not be investigated given our sample size and may explain in part the lack of significant results. The participant group who responded to the survey were quite homogeneous (eg, majority white males aged over 55 and retired), which while fairly reflective of the population accessing CR affects the ability to investigate which patient characteristics are tied to preferences. The National Audit of CR discussed that while over $30 \%$ of patients registered are over 75 and patients have a mean age of 67 (range 18-105), RCTs tend to consider younger age groups. ${ }^{4}$ This issue is present in our sample, as only a single participant was aged over 75 . Further preference research could benefit from increasing recruitment in older age categories. The survey had a higher proportion of female responses compared with patients accessing CR (27.8\% females in England) but reflected the population in the feasibility trial. ${ }^{4}$ One of the comments received from a participant prompted us to consider whether this sample was the most relevant for the study. We invited trial participants and while these are a very relevant group, as they have lived experience, they are less heterogeneous compared with the population who will be offered CR. Furthermore, as highlighted by the participant comment, our participants experienced their cardiac event years previously, and may have recovered or adapted to their condition which could affect their preferences. Further research could explore this by using a larger sample that included other relevant groups (eg, the general public or people who have very recently experienced a cardiac event).

Future research should be wary of the length of survey materials. Participants were asked to respond to 16 choice set questions and some comments noted that the survey felt repetitive. In future, a blocking design may help to reduce the burden of completion and could also help to reduce the sample size needed. Furthermore, we would encourage future researchers to recruit a larger and more varied sample of participants. In particular, we would encourage research to explore whether the timing of preference research affects preferences, for example, whether people have yet to attend or have completed CR. Exploring the association between the severity of depression and/or anxiety, and previous history of depression and/or anxiety, would help to identify preference heterogeneity between groups with and without experience of 
mental illness. DCEs are limited in terms of the number of attributes and levels that can feasibly be included; a review found a median of five attributes included. ${ }^{8}$ This pilot study included attributes based on a qualitative feedback and PPI feedback, as well as discussion with the trial research team. Given the heterogeneity in the delivery of CR and the range of psychological interventions that could be implemented, future research could add or use attributes focusing on more specific details of psychological therapy ${ }^{639}$ Preference research should be considered alongside evidence on the clinical and cost-effectiveness of additions to CR.

While there are a number of limitations, the pilot study fulfils its objectives by establishing the feasibility of a DCE in this participant group; identifying potential attributes, levels and sample sizes and patient groups. As well as providing some information on the potential strengths of preferences for different attributes and levels. To the authors' knowledge this is the first DCE to examine the preferred delivery of psychological therapy in the population attending CR. It demonstrates the potential of research of this type in informing future intervention design, however more research, in particular larger studies with more diverse samples, is needed.

\section{CONCLUSIONS}

This pilot study demonstrates the feasibility of conducting DCEs in this participant group and provides initial evidence for preferences related to the delivery of psychological therapy in CR. Statistically significant results demonstrated participants wanted to receive some information about psychological therapy prior to starting therapy and preferred to receive options with a lower cost to the NHS. Furthermore, the sampled participants tend to favour home-based psychological therapy in CR, with quicker start times and online or smartphone assisted therapy, though these results were not statistically significant. Finally, results indicated that participants would prefer to partake in a therapy compared with no therapy. Results are limited due to the sample recruited. Further research is needed to strengthen conclusions and investigate preference heterogeneity.

\section{Twitter Gemma Elizabeth Shields @gemmaeshields}

Acknowledgements We are very grateful to the PATHWAY PPI members (past and present), and PATHWAY PPI coordinators Tracey Williamson, Carolyn Gamble and Lindsey Brown for assisting with PPI activities that informed this work, as well as the wider PATHWAY team.

Contributors AW and LMD conceived the idea for the research project. AW is the chief investigator in the PATHWAY project. AW, GES, LMD, PD and LC designed and facilitated the experiment in part or in full. SW and GES conducted the analysis. GES and SW drafted the first version of the manuscript and all authors contributed to the subsequent versions. All authors read and approved the final manuscript.

Funding This paper presents independent research funded by the National Institute for Health Research (NIHR) under its Programme Grants for Applied Research (PGfAR) Programme (Grant Reference Number RP-PG-1211-20011). The views expressed are those of the authors and not necessarily those of the NIHR or the Department of Health.
Competing interests All authors have completed the ICMJE uniform disclosure form at www.icmje.org/coi_disclosure.pdf and declare no support from any organisation for the submitted work (with the exclusion of the stated funder), no financial relationships with any organisations that might have an interest in the submitted work in the previous 3 years and no other relationships or activities that could appear to have influenced the submitted work.

Patient consent for publication Not required.

Ethics This study was reviewed and given a favourable ethical opinion for conduct in the NHS by NRES Committee North West-Greater Manchester West (reference number: 16/NW/0786).

Provenance and peer review Not commissioned; externally peer reviewed.

Data availability statement Anonymised data are available on reasonable request from the corresponding author.

Open access This is an open access article distributed in accordance with the Creative Commons Attribution 4.0 Unported (CC BY 4.0) license, which permits others to copy, redistribute, remix, transform and build upon this work for any purpose, provided the original work is properly cited, a link to the licence is given, and indication of whether changes were made. See: https://creativecommons.org/ licenses/by/4.0/.

ORCID iD

Gemma Elizabeth Shields http://orcid.org/0000-0003-4869-7524

\section{REFERENCES}

1 Roth GA, Mensah GA, Johnson CO, et al. Global burden of cardiovascular diseases and risk factors, 1990-2019: update from the GBD 2019 study. J Am Coll Cardiol 2020;76:2982-3021.

2 Dalal HM, Doherty P, Taylor RS. Cardiac rehabilitation. BMJ 2015;351:h5000.

3 Shields GE, Wells A, Doherty P, et al. Cost-effectiveness of cardiac rehabilitation: a systematic review. Heart 2018;104:1403-10.

4 British Heart Foundation. National audit of cardiac rehabilitation (NACR) report 2019 - BHF, 2019. Available: https://www.bhf.org.uk/ informationsupport/publications/statistics/national-audit-of-cardiacrehabilitation-quality-and-outcomes-report-2019 [Accessed 07 Feb 2020].

5 Anderson L, Sharp GA, Norton RJ, et al. Home-based versus centre-based cardiac rehabilitation. Cochrane Database Syst Rev 2017;6:CD007130.

6 Albus C, Herrmann-Lingen C, Jensen K, et al. Additional effects of psychological interventions on subjective and objective outcomes compared with exercise-based cardiac rehabilitation alone in patients with cardiovascular disease: a systematic review and metaanalysis. Eur J Prev Cardiol 2019;26:1035-49.

7 de Bekker-Grob EW, Ryan M, Gerard K. Discrete choice experiments in health economics: a review of the literature. Health Econ 2012;21:145-72.

8 Soekhai V, de Bekker-Grob EW, Ellis AR, et al. Discrete choice experiments in health economics: past, present and future. Pharmacoeconomics 2019;37:201-26.

9 Lancaster KJ. A new approach to consumer theory. J Polit Econ 1966;74:132-57.

10 Boyde M, Rankin J, Whitty JA, et al. Patient preferences for the delivery of cardiac rehabilitation. Patient Educ Couns 2018;101:2162-9.

11 Kjaer T, Gyrd-Hansen D. Preference heterogeneity and choice of cardiac rehabilitation program: results from a discrete choice experiment. Health Policy 2008;85:124-32.

12 Kjaer T, Gyrd-Hansen D, Willaing I. Investigating patients' preferences for cardiac rehabilitation in Denmark. Int J Technol Assess Health Care 2006;22:211-8.

13 Whitty JA, Stewart S, Carrington MJ, et al. Patient preferences and willingness-to-pay for a home or clinic based program of chronic heart failure management: findings from the Which? trial. PLoS One 2013;8:e58347.

14 Tang LH, Kikkenborg Berg S, Christensen J, et al. Patients' preference for exercise setting and its influence on the health benefits gained from exercise-based cardiac rehabilitation. Int $J$ Cardiol 2017;232:33-9.

15 BHF. National audit of cardiac rehabilitation (NACR) report 2020, 2014. Available: https://www.bhf.org.uk/informationsupport/ publications/statistics/national-audit-of-cardiac-rehabilitationquality-and-outcomes-report-2020 [Accessed 27 Apr 2021].

16 Wells A, McNicol K, Reeves D, et al. Metacognitive therapy homebased self-help for cardiac rehabilitation patients experiencing 
anxiety and depressive symptoms: study protocol for a feasibility randomised controlled trial (pathway home-MCT). Trials 2018;19:444.

17 Wells A, McNicol K, Reeves D, et al. Improving the effectiveness of psychological interventions for depression and anxiety in the cardiac rehabilitation pathway using group-based metacognitive therapy (PATHWAY group MCT): study protocol for a randomised controlled trial. Trials 2018;19:215.

18 Shields GE, Wells A, Doherty P, et al. Protocol for the economic evaluation of metacognitive therapy for cardiac rehabilitation participants with symptoms of anxiety and/or depression. BMJ Open 2020;10:e035552.

19 McPhillips R, Salmon P, Wells A, et al. Qualitative analysis of emotional distress in cardiac patients from the perspectives of cognitive behavioral and metacognitive theories: why might cognitive behavioral therapy have limited benefit, and might metacognitive therapy be more effective? Front Psychol 2018;9:2288.

20 McPhillips R, Salmon P, Wells A, et al. Cardiac rehabilitation patients accounts of their emotional distress and psychological needs: a qualitative study. J Am Heart Assoc 2019;8:e011117.

21 Shields GE, Brown L, Wells A, et al. Utilising patient and public involvement in stated preference research in health: learning from the existing literature and a case study. Patient 2021;14:399-412.

22 Russell KL, Holloway TM, Brum M, et al. Cardiac rehabilitation wait times: effect on enrollment. $J$ Cardiopulm Rehabil Prev 2011;31:373-7.

23 Marzolini S, Blanchard C, Alter DA, et al. Delays in referral and enrolment are associated with mitigated benefits of cardiac rehabilitation after coronary artery bypass surgery. Circ Cardiovasc Qual Outcomes 2015;8:608-20.

24 Collins ZC, Suskin N, Aggarwal S, et al. Cardiac rehabilitation wait times and relation to patient outcomes. Eur J Phys Rehabil Med 2015;51:301-9.

25 Lancsar E, Louviere J. Conducting discrete choice experiments to inform healthcare decision making. Pharmacoeconomics 2008;26:661-77.

26 Reed Johnson F, Lancsar E, Marshall D, et al. Constructing experimental designs for discrete-choice experiments: report of the ISPOR conjoint analysis experimental design good research practices task force. Value in Health 2013;16:3-13.
27 van Hout B, Janssen MF, Feng Y-S, et al. Interim scoring for the EQ$5 \mathrm{D}-5 \mathrm{~L}$ : mapping the EQ-5D-5L to EQ-5D-3L value sets. Value Health 2012;15:708-15.

28 EuroQol. NICE position statement on the EQ-5D-5L - EQ-5D. Available: https://euroqol.org/nice-position-statement-on-the-eq-5d5l/ [Accessed 06 Nov 2019].

29 de Bekker-Grob EW, Donkers B, Jonker MF, et al. Sample size requirements for discrete-choice experiments in healthcare: a practical guide. Patient 2015;8:373-84.

30 NGene C. Conducting discrete, 2019. Available: http://www.choicemetrics.com/

31 Lancsar E, Louviere J. Conducting discrete choice experiments to inform healthcare decision making: a user's guide. Pharmacoeconomics 2008;26:661-77.

32 Bech M, Gyrd-Hansen D. Effects coding in discrete choice experiments. Health Econ 2005;14:1079-83.

33 van der Pol M, Currie G, Kromm S, et al. Specification of the utility function in discrete choice experiments. Value Health 2014;17:297-301.

34 Janssen B, Szende A. Population norms for the EQ-5D. In: Selfreported population health: an international perspective based on EQ-5D. Springer Netherlands: Dordrecht:, 2014: 19-30.

35 Menzel P, Dolan P, Richardson J, et al. The role of adaptation to disability and disease in health state valuation: a preliminary normative analysis. Soc Sci Med 2002;55:2149-58.

36 Helgesson G, Ernstsson O, Åström M, et al. Whom should we ask? a systematic literature review of the arguments regarding the most accurate source of information for valuation of health states. Qual Life Res 2020;29:1465-82.

37 Buys R, Claes J, Walsh D, et al. Cardiac patients show high interest in technology enabled cardiovascular rehabilitation. BMC Med Inform Decis Mak 2016;16:95.

38 Tünneßen M, Hiligsmann M, Stock S, et al. Patients' preferences for the treatment of anxiety and depressive disorders: a systematic review of discrete choice experiments. J Med Econ 2020;23:546-56.

39 Pedersen SS, Doyle F. Effectiveness of psychological intervention as add-on to standard cardiac rehabilitation: time to adopt new methods or keep doing more of the same? Eur J Prev Cardiol 2019;26:1032-4. 